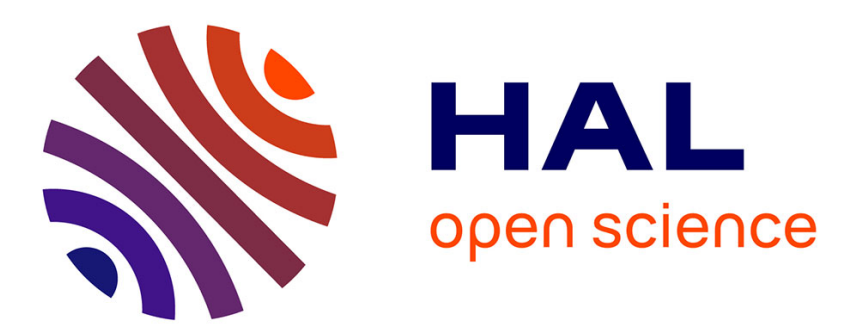

\title{
A la búsqueda del 'Genio de España': Giménez Caballero, psicógrafo superrealista de Manuel Azaña
}

Manuel Pulido Mendoza, Manuel Pulido Mendoza

\section{To cite this version:}

Manuel Pulido Mendoza, Manuel Pulido Mendoza. A la búsqueda del 'Genio de España': Giménez Caballero, psicógrafo superrealista de Manuel Azaña. Bulletin of Hispanic Studies, 2011, 88 (1), pp.43-58. 10.3828/bhs.2010.46 . hprints-02352535

HAL Id: hprints-02352535

https://hal-hprints.archives-ouvertes.fr/hprints-02352535

Submitted on 6 Nov 2019

HAL is a multi-disciplinary open access archive for the deposit and dissemination of scientific research documents, whether they are published or not. The documents may come from teaching and research institutions in France or abroad, or from public or private research centers.
L'archive ouverte pluridisciplinaire HAL, est destinée au dépôt et à la diffusion de documents scientifiques de niveau recherche, publiés ou non, émanant des établissements d'enseignement et de recherche français ou étrangers, des laboratoires publics ou privés. 
See discussions, stats, and author profiles for this publication at: https://www.researchgate.net/publication/275990030

\section{A la búsqueda del 'Genio de España': Giménez Caballero, psicógrafo superrealista de Manuel Azaña}

Article · January 2011

DOI: $10.3828 /$ bhs. 2010.46

1 author:

\section{Manuel Pulido Mendoza}

Francisco Marroquín University

55 PUBLICATIONS 5 CITATIONS

SEE PROFILE
READS

503

Some of the authors of this publication are also working on these related projects:

Project Libro sobre Ortega y Gasset View project

Project Estudios biográficos View project 


\title{
A la búsqueda del 'Genio de España': Giménez Caballero, psicógrafo superrealista de Manuel Azaña*
}

\author{
MANUEL PULIDO MENDOZA
}

Universidad de Extremadura

\begin{abstract}
Resumen
Ernesto Giménez Caballero fue uno de los primeros elaboradores sistemáticos de la leyenda negra de Manuel Azaña. Para ello, se sirvió en su Manuel Azaña: Profecías españolas (1932) de varios procedimientos constructivos que luego serán profusamente copiados por la 'historiografía' franquista y revisionista. Estos lugares comunes se asocian a tres tipos diferentes de recursos literarios: Primero, la lectura fragmentaria, equívoca y descontextualizada de la obra del Azaña escritor. Su obra de ficción escrita en primera persona es tomada intencionadamente como literatura autobiográfica. De modo añadido, Giménez Caballero también se vale de un falso registro testimonial para añadir credibilidad a algunas anécdotas denigratorias sobre Azaña. En segundo lugar, aplica a su literatura las ideas (para)científicas de su época, en especial la psicopatología fisionómica y la 'psicografía' freudiana. El tercer y último recurso es el uso de la etopeya deformante y caricaturesca, mediante el empleo de técnicas de las vanguardias artísticas y literarias.
\end{abstract}

\footnotetext{
Abstract

Ernesto Giménez Caballero was one of the first systematic creators of Manuel Azaña's black legend. In his Manuel Azaña: Profecías españolas (1932) he used several constructive procedures, which were to be extensively copied by Francoist and revisionist 'historiography'. These commonplaces can be grouped into three different literary devices: first, the fragmentary, equivocal misreading of Manuel Azaña's written works in which his first-person fiction is intentionally taken as autobiographical writing. Furthermore, Giménez Caballero also used a false-witness account to add credibility to some degrading anecdotes about Azaña. Secondly, he applies to his

* El presente artículo forma parte de un proyecto de investigación más amplio sobre la representación deforme de la figura de Manuel Azaña Díaz, surgido a partir de la tesis Plutarco de moda. La biografía moderna en España (1900-1950) (Mérida, Cáceres: Editora Regional de Extremadura/ Servicios de Publicaciones UEX, 2009), financiada por la Junta de Extremadura con una beca predoctoral de cuatro años y por la beca de la Residencia de Estudiantes/Ayto. de Madrid de tres años).
} 
literature the (para)scientific ideas of his age, especially physiognomic psychopathology and Freudian 'psychography'. The third and last resource is the use of a deforming and caricaturesque portrait created through techniques common to the artistic and literary avant-garde.

Y por qué no osar darse otras explicaciones de la República española que superen el sentido histórico y el sentido doctrinario hasta ahora vigente? ¿Por qué no disponerse a un análisis más que real y más que ideal del fenómeno español? Un análisis ¿superrealista? ¿Intra-psíquico? [...] No son, pues, los errores de la dinastía borbónica, ni la cultura minoritaria en progresión, las causas fundamentales de la República española. No ha sido esta República un 'asunto de cultura y sensibilidad', sino un caso genuino de ‘sexualidad y autoritarismo’ (Giménez Caballero 1975: 30; 39 [énfasis en el original]).

Ernesto Giménez Caballero, convertido ya totalmente al fascismo, había exhortado decididamente a una resurrección dictatorial de España y del mundo en su Genio de España (1932a). Una vez publicada esta exaltación, el autor se puso, al contrario de los personajes de Pirandello, a buscar el protagonista que pudiera encarnar tal proyecto. Tan sólo unos meses más tarde, ya había encontrado el comienzo del hilo de esa resurrección en su biografía Manuel Azaña: Profecías españolas (1932b). El 'psicógrafo', 'loco de videncia' (1975: 34), creía haber encontrado el hombre que pudiera encarnar un proyecto de 'modernización' autoritaria para el país. La comparación con líderes revolucionarios de otros países, le permitió una momentánea adhesión a Manuel Azaña, que en realidad nunca fue sin reservas (Serrano 1993: 199-200), ni correspondida, a tenor de lo que ambos personajes dejaron escrito, ${ }^{1}$ sobre todo tras su ofrecimiento infructuoso de ser el poeta del caudillo autoritario que él estaba 'profetizando' (Selva 2000: 167).

La intención de Giménez Caballero había sido escribir la primera biografía laudatoria del Duce español, del mismo modo que su querida amiga, la periodista Margherita G. Sarfatti, había hecho con la primera biografía de Mussolini, DVX (1926; véase Sarfatti 1932). ${ }^{2}$ Giménez se servirá de esta tradición italiana

1 Además de en La Gaceta Literaria, el escritor adelantó su análisis del político en diversos diarios madrileños (El Sol, Heraldo de Madrid, Informaciones) a cuyos directores dedica el libro (Giménez Caballero 1975: 7). Aunque Gecé asegura que 'Azaña lo leyó y, atentamente, me dió las gracias' (1975: 59), él mismo volvió a referirse a su libro en un artículo de 1935 en Informaciones sin las calculadas ambigüedades de comienzo de su 'campaña' azañista: 'Se habla mucho de Azaña como de un déspota, de un dictador, de un traganiños (1935a). Todo el mundo sabemos [sic] que eso es mentira. Y si alguien mejor que nadie lo sabe, soy yo. Yo, que le ofrecí un libro como una soberbia marca de bólido de carreras y, ofendido, me lo tiró a la cabeza. Porque era el carro [de las dos ruedas del turnismo liberal-conservador] su ideal. Si su ideal hubiera sido otro, no hubiera tolerado desde el Poder a su supuesto enemigo, la Ceda [sic, C.E.D.A.]. En realidad, la ayudó cuanto pudo, ya que no veía otro partido conservador viable para la República' (Giménez Caballero 1935: 1). Azaña posiblemente recibiera los artículos con discreción y educación, pero en sus memorias, en efecto, tacha los adelantos del libro de 'lunáticos' y de 'estúpido[s]' (Azaña 2004: 362; 548).

2 El modelo es claro en la comparación entre la revolución soviética y el fascismo, como formas que debían lograr, tras la I Guerra Mundial, la modernización industrial por vías autoritarias (Sarfatti 1932: 10). El propio Giménez prologó esta biografía mussoliniana en 
(Pagliara 2001: 33-34), pero adaptándola al entorno español de 1932. En ambos casos, existe un mismo interés por esta transferencia psicológica que llevase, bien a la admiración fetichista, bien al odio irracional de la figura biografiada. Vemos un similar interés en el relato novelesco de la educación y del desarrollo de la personalidad. En los dos casos existe un mismo enfoque pedagógico fascista en el modelo - Mussolini - y el anti-modelo - Azaña -. Los patrones seguidos por el neoclasicismo fascista eran la Vida de los Césares y los Panegíricos de la literatura latina. La asociación entre físico deforme y moralidad depravada, y entre ésta y los ataques políticos, es, al menos, tan antigua como Salustio (1997: 76-77 y 85) y sus célebres retratos de Catalina y Jugurta, así como la Invectiva contra Cicerón de Pseudo Salustio. Estas resonancias clásicas se encuentran de igual modo en su falso panegírico a Azaña. En numerosas ocasiones, además, Giménez Caballero volvería a los paralelismos entre la sucesión de monarquía, república e imperio de la historia romana clásica y la historia del siglo XX español (Giménez Caballero en Giménez Caballero y Selva 1988: 25). Indudablemente veía a Manuel Azaña como un Orestes o un Cicerón ibérico, y se percibía a sí mismo como una especie de Esquilo o Salustio español, como el vate o cronista de la tragedia española. Por tanto, su dedicatoria a la figura de Azaña es hipócrita y falsa. Se sirvió de ella de modo retórico, para escenificar una decepción y un rechazo que justificara, a posteriori, este duro libelo así como la llamada a una figura cesárea que lo sustituyera. La labor formaba parte de una campaña internacional de desprestigio de Azaña, comenzada por la revista oficial del fascismo italiano Gerarchia, en la que Giménez Caballero comenzó a colaborar (1932c y 1933) por mediación de su admirada amiga, la periodista y biógrafa italiana señalada, que era amante del no menos admirado Curzio Malaparte. ${ }^{3}$

Lo que primero llama la atención del ensayo biográfico de Giménez Caballero es la documentación usada y el modo en el que la emplea. Aunque Giménez Caballero (1975: 10) afirma en su segunda edición no haber llegado nunca a leer a su inmediato antecedente en la construcción de la leyenda negra azañista, la biografía de Azaña escrita por Nicolás González Ruiz (1932), no podemos estar seguros de su sinceridad, si atendemos a sus declaraciones expresas aparecidas

su primera edición española de 1938, quizás en agradecimiento por los servicios prestados en su fuga clandestina de la España fiel a la República en el fatídico verano de 1936 (Tandy and Sferrazza 1977: 149).

3 Por si hubiera duda sobre la finalidad propagandística del libro sobre Azaña, el propio Giménez Caballero le escribe a Francisco Franco en septiembre de 1937: 'Si volviese a los tiempos de Azaña en 1932, volvería a escribir ese mismo [libro] que espero ofrecérselo a $S$. E. si lo encuentro. Mi deber de fascista - como el de católico con el pagano - era de intentar toda posible catequización para los fines de la causa. Ni existía José Antonio, ni Gil Robles, ni nadie en el área política. De acuerdo con la alta directiva política fascista de Italia (el embajador Guariglia, hoy en Argentina, sabe esto) - abordé la catequesis de aquel monstruo. Y algo obtuvimos a la larga. Aunque a mí me mandó meter en la cárcel de Ocaña, escapando por milagro' (Informe de Ernesto Giménez Caballero al general Franco sobre la situación política, fechado en septiembre de 1937, Archivo EGC, Madrid, apud Selva 2000: 190). 
en la primera edición. ${ }^{4}$ Por las reseñas anónimas aparecidas en la prensa (1932a, 1932b, 1932c), sabemos que fue publicada con varios meses de antelación a la de Giménez y difícil sería que alguien tan informado de la actividad cultural del país, al menos, no le hubiera echado un vistazo antes. En cualquier caso, el uso tergiversado de las fuentes es común a ambos libros. Ambos interpretan los textos ficticios escritos en primera persona por Azaña como confesiones del autor, contraviniendo toda diferenciación lógica entre autor y la voz diegética dentro de las ficciones literarias.

Tras citar las obras de artículos y discursos de contenido político escritos por el alcalaíno, como fuentes para descifrar la personalidad política de Azaña, Gecé indica que, para comprender su pensamiento religioso, había que volver a $\mathrm{El}$ jardín de los frailes. En el apartado titulado ‘El Escorial y el monstruo’, Giménez encuentra, al igual que González, unas memorias infantiles encriptadas y toma al personaje ficticio protagonista por el propio Azaña (Giménez Caballero 1975: 45-46). No obstante, si retomamos la novela de Manuel Azaña, la única parte del texto que puede leerse en clave referencial, esto es, autobiográfica, sería el prólogo. En él, Azaña deja bien claro no haber sucumbido ni a la autobiografía, ni a la confesión disfrazada de novela autobiográfica (Azaña 1990, I: 665; Marichal en Azaña 1990: LXXXIX).

Estas son las fuentes biográficas de Giménez Caballero para su tratamiento 'objetivo' de Azaña: comentarios, anécdotas, rumores, obras literarias (Giménez Caballero 1975: 139). Junto con la anécdota de la botella en el vagón de regreso a Madrid, ${ }^{5}$ y la del encuentro con Giménez Caballero en el ministerio de Gracia y Justicia cuando fue a registrar su Gaceta Literaria, se incluyen otras en donde rumores o comentarios se dan por hechos fehacientes (42), al igual que algunas anécdotas intentan dar credibilidad a verdaderas falsedades sobre Azaña (188).

Junto con el uso tramposo de las convenciones de la literatura autobiográfica y referencial, el segundo elemento constructivo de la obra de Giménez Caballero sobre Azaña fue el apoyo en las convenciones de la literatura (para)científica de la época. Los referentes manejados por Giménez Caballero son esencialmente cuatro, aunque se podría rastrear algún otro: Theodor Lothrop Stoddard, Gregorio Marañón, Gonzalo R. Lafora, Hans Von Hentig y, sobre todo, Sigmund Freud.

Stoddard, a quien cita erróneamente como 'Stoddad' (sic, 1975: 142) fue un eugenista norteamericano que expuso en numerosas obras ideas racistas sobre la supremacía blanca. La idea de las tres etapas de todo proceso revolucionario citada por Giménez en su biografía de Azaña fue extraída con toda probabilidad

4 '[U]tilicé cuanto Azaña ha escrito y dicho, o se ha dicho y escrito sobre Azaña hasta el presente' (Giménez Caballero 1975: 23).

5 'Después tuve otro encuentro (que relaté en mi libro sobre él) a la vuelta del viaje a Cataluña en 1930 que La Gaceta Literaria había organizado con los intelectuales castellanos. Cuando sentado con él en una mesa del vagón restaurante, acompañados por Gutiérrez Abascal y Álvarez del Vayo, le llamé tirano al querer romper, con el mango del cuchillo, el gollete de una botella de vino porque el pobre camarero tardaba en hacerlo con el sacacorchos' (Giménez Caballero 1979: 89). Véase también al respecto la conferencia de Giménez Caballero 1980: 7; 99-100), y Giménez Caballero 1975: 44. 
de su obra publicada en España en 1926. En ella asociaba estudios procedentes de la genética, la biología, la endocrinología, la psicología, la sociología y la historia para ilustrar sus teorías peregrinas sobre la decadencia civilizatoria que conllevaba el mestizaje racial, el determinismo endocrino en la formación del carácter y la moralidad, así como la psicopatología aplicada a la comprensión de los fenómenos históricos. Para él las atrocidades cometidas por los comisarios bolcheviques y sus ‘hordas asiáticas' sólo parecían explicables mediante el psicoanálisis, como una 'perversión sexual llamada sadismo' (Stoddard 1926: 158-59). Claramente se puede ver la influencia de esta inspiración en su libro sobre el Presidente Azaña y la llegada de la República.

El libro que el psicopatólogo Hans Von Hentig había publicado en la Editorial España en el año 1930 debió de servirle también como ejemplo para su libelo. Este libro dedicado a Robespierre, curiosamente, se anunciaba en prensa junto con una traducción de las Confesiones de Georges Clemenceau hecha por el mismo Manuel Azaña. ${ }^{6}$ No se ha estudiado todavía la influencia de este libro en el quehacer memorialístico de Manuel Azaña, como tampoco la que el modelo de biografía psicopatológica pudo tener en el libro de Giménez Caballero. De momento podemos constatar que el texto del madrileño está repleto de referencias a la vida de Robespierre, con la que el autor realizó numerosos paralelismos. La figura del republicano sanguinario le venía como anillo al dedo en su caracterización de Azaña como déspota de la tradición ilustrada. Como siempre, la explicación a este comportamiento reside en un determinismo psicoanalítico presentado como indiscutible (Gonzalo R. Lafora en Von Hentig 1930: 8), reforzado por la endocrinología asociada a la biotipología de Ernst Kretschmer. Lafora, en su prólogo a la obra de Von Hentig, señala:

Esta frigidez de erótica eunucoide de Robespierre se cristaliza, como en Cromwell, Torquemada y en su contemporáneo Chaumette o en Catalina Theot, en un odio a toda sexualidad, al placer. Es un resentimiento, del que deriva la idea sistemática de procurar la felicidad de la humanidad mediante una moral rígida, sólo posible de alcanzar imponiéndola por el dolor y el terror. [...] Dentro de las constituciones psíquicas esquizotímicas, basadas en estructuras corporales, pueden hacerse tres grupos caracteriológicos, siguiendo las ideas de Kretschmer: $1^{\circ}$, los idealistas y moralistas puros, como Kant, Schiller y Rousseau; $2^{\circ}$, los déspotas y fanáticos como Savonarola, Calvino y Robespierre, y $3^{\circ}$, los calculadores fríos, como Federico el Grande. Robespierre es el tipo más representativo de ese grupo de personalidades esquizotímicas, despóticas y fanáticas, dominadas por un pensamiento autístico, disgregado de la realidad y dispuesto a llevarlo a cabo contra toda oposición de la realidad. (Von Hentig 1930: 10-11)

Los argumentos usados por Giménez Caballero en su biografía de Azaña son muy parecidos, y se basan en los mismos principios, por lo que se puede conjeturar la influencia de esta biografía en la redacción de la suya. En especial en lo referente a la psicopatología sexual como fuente del supuesto carácter resentido de ambos

6 El anuncio se encuentra en la página 2 del día 18 de mayo de 1930 del diario madrileño El Sol. Ambos libros (Martet 1930 y Von Hentig 1930), dedicados a Clemenceau y Robespierre, respectivamente, habían sido publicados por la Editorial España. 
personajes: 'Robespierre, como Azaña, estudió para abogado. Y como él fue un muchacho "retraído", de "pocos amigos” y "estudioso”, tuvo, como Azaña, un amor infortunado y no correspondido por una tal Ángela Deshorties. Esta herida le cuajó mucho de su rencor resentido’ (Giménez Caballero 1975: 189).

Aunque en España se encontrarían conclusiones parecidas en otros autores españoles de la 'endocrino-historia', como Gregorio Marañón, al que cita de pasada en un par de ocasiones (37 y 40), acude a la concepción atavística del delito y del delincuente de Lombroso (31) para reforzar este diagnóstico psicopatológico de Azaña. No obstante, su apoyo mayor en este empeño fueron las teorías psiconalíticas de Sigmund Freud. De él surge el intento fallido de psicoanalizar a través de obras artísticas, escritos personales y testimonios contemporáneos al biografiado. Freud aplicó las llamadas 'percepciones' de su teoría a muchos problemas que precedentemente no se había pensado que estuvieran ubicados en el ámbito de la psiquiatría, tales como la explicación del ingenio y el humor, las causas de la guerra, la antropología y, en particular, la investigación de las figuras y acontecimientos históricos en términos de factores motivacionales. Nos referimos a lo que se conoce como psico-historia o psico-biografía; es decir, 'la noción de que podemos obtener una percepción de las vidas de las figuras históricas mediante el uso de los métodos y principios del psicoanalista, y aplicando los métodos psicoanalíticos a la antropología' (Eysenck 1988: 219). El ejemplo clásico de psicobiografía es el ensayo sobre Leonardo Da Vinci escrito por Freud. ${ }^{7}$ Sin embargo, David E. Stannard (apud Eysenck 1988: 227) ha demostrado que,

\begin{abstract}
Freud construyó la mayor parte de su análisis [sobre Leonardo Da Vinci] a modo de una pirámide invertida, cuya completa estructura se balanceaba sobre la piedra maestra de un solo hecho discutible y su interpretación; una vez que se demuestra que este hecho es falso, y es retirado como soporte, todo el edificio comienza a derrumbarse. Y ningún balbuceo retórico ni ninguna pantalla de humo pueden ocultar este proceso de desintegración natural.
\end{abstract}

Es decir, todos sus razonamientos deductivos estaban basados en una premisa falsa, no demostrada, sino inducida, y que remitía en última instancia a teorías no demostradas científicamente como la del complejo de Edipo. El libro de Freud sobre Leonardo da Vinci ejemplifica de una manera curiosa los cuatro grandes conjuntos de problemas que presenta la psico-historia de inspiración freudiana. Stannard ha demostrado con rigurosidad científica cómo la psico-historia presenta problemas de hecho, de lógica, de teoría y de cultura para la validez universal de sus afirmaciones. Desde un punto de vista rigurosamente científico, la teoría de Freud, concluye Eysenck (1988: 245), debe ser 'juzgada basándose en la lógica, en la consistencia y en el respaldo fáctico'.

El biógrafo de Azaña (Giménez Caballero 1975: 32) toma de Freud las bases mitológicas y etnológicas que sustentan la teoría psicoanalítica del complejo de Edipo, y comete el mismo tipo de errores que estos críticos señalan en la psico-

7 Originalmente publicado en 1910 con el título Eine Kindheitserinnerung des Leonardo da Vinci, es muy posible que Giménez Caballero (1975: 32) consultara la edición española de 1923 en el volumen que contenía también Tótem y tabú (Freud 1923). 
historia y la antropología freudiana. La toma de la ficción en primera persona por documento autobiográfico, como hemos visto, es un claro error en la validación de los datos. En una obra que se pretende referencial, como una biografía, es un acto de flaqueza intelectual y moral tomar suposiciones e invenciones propias y ajenas y considerarlas hechos probados. En cuanto a los fallos de lógica, se puede exponer la disparatada afirmación de que el líder republicano, un demócrata liberal y laicista convencido, fuese un déspota autoritario y católico, del que llega a afirmar que fuera 'el último gran fenómeno católico de España' (24), y que supuestamente habría compartido con Felipe II, no sabemos si como crítica o como elogio, 'el carácter axiomático, fanático, sectario, tiránico, dogmático, del gran rey austriaco' (187). En cuanto a los fallos de teoría, parece claramente inadecuado el uso del complejo de Edipo en la explicación del advenimiento de la República. Va contra todo empirismo afirmar que el complejo de Edipo pueda explicar la conducta humana individual y colectiva. Por lo que es doble o triplemente incoherente y mendaz trasladar dicho complejo a la explicación del progreso de las culturas primitivas, 'totémicas', y de ahí dar el salto sin transición a la historia contemporánea española (33 y 34). No basta una analogía metafórica para establecer una teoría científica, sino que ésta última debe someterse a pruebas de comprobación y validación universal a partir de unas condiciones dadas y reproducibles. En cuanto a los errores de interpretación cultural o realizada fuera de contexto, se podrían argüir como ejemplos las anécdotas personales de Giménez Caballero sobre el político y escritor. Fuera cierta o no la anécdota de la botella, en sí no constituye soporte válido para calificar a Azaña de 'demócrata violento' o de 'tirano', como hace el autor en su libro.

Pese a todo, el psicoanálisis no es del todo estéril, en tanto que, como discurso legitimador de una serie de puntos de vista, nos sirve paradójicamente para descubrir más las ansiedades y preocupaciones del psicoanalizador que del psicoanalizado (Eysenck 1988: 245). Como ha señalado Jo Labanyi (1996), Giménez Caballero ha sido uno de los primeros escritores españoles que leyeron y creyeron seriamente las teorías de Sigmund Freud, cuyas Obras Completas estaban siendo publicadas traducidas al español desde 1923. Aunque más que la supuesta aplicación terapéutica o 'científica' de las teorías de Sigmund Freud, lo que atrajo a Giménez Caballero fue la posibilidad de fundar un discurso que, suprimiendo las trabas del racionalismo empírico, fuese literaria y políticamente productivo. El madrileño, al ser preguntado por la inspiración del que ha sido considerado el primer libro surrealista español - Yo, inspector de alcantarillas (1928) -, respondió:

Es la aplicación revolucionaria de las teorías de Freud, que deshace la integridad de la persona humana y deja como valioso el mundo de los sueños, de lo incoherente, la anulación de la razón. Y buscando en esto precisamente la poesía; entendiendo por poesía lo irracional, lo ininteligible, lo subconsciente. Al llegar a mí, no lo hizo por medio de libros ni imitaciones, sino que yo reelaboré este mundo a mi modo, inspirándome, como digo en el libro, en la mística española. (Giménez Caballero y Selva 1988: 23-24) 
La mezcla de argumentos políticos e imágenes sexuales en sus obras es uno de los motivos que convierten a este autor en uno de los más incómodos de abordar en los estudios literarios, aunque, a juicio de Labanyi (1996: 378), no por eso debe ser evitado. Según esta autora, el uso explícito de imaginería sexual en su obra sirve para proponer el fascismo, esto es, el encuadramiento vertical de la sociedad en una estructura autoritaria como un antídoto para el miedo masculino a la aniquilación del dominio autoritario patriarcal (381). Sus ideas políticas se mantienen dentro de la apelación fascista a las fuerzas irracionales, en el campo de la sexualidad más que en el de lo social o lo económico (386). La bien estructurada retórica de Genio de España muestra a Giménez Caballero 'consciously manipulating psychological complexes for political effect' (380), del mismo modo que lo hace en su obra inmediatamente posterior sobre Azaña. Giménez Caballero propone como solución a la crisis de la modernidad la unión de toda la sociedad a través de una estructura de dominación, para lo que era necesario encontrar un caudillo. Como muy bien ha señalado Julio RodríguezPuértolas (1986: 95-96), el libro sobre Azaña respondía a 'la típica necesidad fascista de un padre, violento y justo’ que ya había sido apuntada en su ensayo anterior (Giménez Caballero 1932a: 68). Así lo declaraba también la biografía de Azaña, a la que consideraba 'continuación periódica de mi Robinsón Literario, de mi Genio de España' (1975: 23-24). En efecto, tal como señala Labanyi y como explícitamente afirma Giménez Caballero en su libro sobre Azaña, la política para él es una cuestión de 'sexualidad y autoritarismo' (39) o ‘de sexo y de poder' (40).

En la explicación psicoanalítica de la República que ofrece, asocia la figura patriarcal originaria - el Urvater - con el dictador Miguel Primo de Rivera. Éste habría sido sustituido por un latente enfrentamiento fraticida conjurado por una fase transitoria de matriarcado:

De ahí que, para contrarrestar la fatal ferocidad autofágica de las fatrias, fuese menester, como en toda auténtica República, la vaga instauración de un Matriarcado. De signo femenino, maternal, que suavizase y enmolleciese los instintos eruptivos de los machos en libertad.

El Matriarcado de nuestra República ha venido consistiendo, como en las otras auténticas Repúblicas, en cristalizar el poder en una Mítica de sexo femenino. [...] Por el contrario, quedaron relegados a sospecha, vigilancia o desuetud, los elementos más netamente virófilos [sic] y agresores: sindicalistas, militares, ingenieros, empresarios[...] (Giménez Caballero 1975: 36-37)

Dentro de este discurso, el presidente de la República, Niceto Alcalá Zamora, habría quedado como símbolo intangible del patriarcado extinto o en vías de extinción, como 'símbolo totémico de la Realeza' (37). Su filiación fascista y autoritaria se puede interpretar como una reacción edípica ante la amenaza al patriarcado, que supuestamente suponía la implantación de la democracia en España. La ansiedad que esta situación de orfandad patriarcal le produce a Giménez Caballero se deduce de una serie de preguntas retóricas y a las que intenta responder con esta biografía de Azaña: 
¿Podrá España soportar por mucho tiempo esta protección matriarcoide en las alturas? ¿Podrá la tradicional España de Don Juan la victoria del sexo contrario? [...] $1^{a}$ ¿Se despedazarán las fratrías actuales, como es tradición española en situaciones parecidas anteriores (tribus ibéricas, cabilismo, reinos de taifas, comuneros, cantonalismo, República del 73)? 2a , ¿Emergerá otra vez el postulado tradicional del ‘aquí hace falta un hombre’? 3aa ¿Se llegará a un equilibrio de poderes? [...] ¿Será capaz Azaña de seguir ese camino? ¿De retroceder? ¿De desviarse? ¿De desarrollar su determinismo totémico hasta los límites insospechables? ¿De arrojar un día la máscara trágica? [...] ¿Qué hará el escritor Manuel Azaña, presidente del Gobierno? (1975: 39; 40; 57; y 58)

En estos momentos, obcecado en su búsqueda desesperada de un líder autoritario, tildará a Manuel Azaña de falso demócrata - 'criptomonócrata' le llega a llamar - y de 'padre de la República' (40 y 41). Sin embargo, conforme avance en la escritura del libro constatará el hecho de que Azaña no era ese hombre anhelado. Por esto tornará el inicial panegírico en cruel libelo.

Junto con la mistificación documental leída en clave autobiográfica y el psicoanálisis retrospectivo, el tercer elemento constructivo de la psico-biografía de Giménez Caballero fue la estética de la vanguardia literaria y sus técnicas. El primero de estos procedimientos, que ya hemos tratado en los dos elementos anteriores, es el desplazamiento espacial entre significados y significantes, así como el desplazamiento temporal al obviar el orden o sucesión cronológicacausal por una muy conveniente simultaneidad temporal. Éstas técnicas estéticas de la vanguardia procedían de la nueva visión y modos de representación que supuso la difusión de los avances técnicos de la reproducción mecánica de la imagen (Gubern 1999; cfr. con la copia del collage de la portada original reproducida en Trapiello 2002: 64).

El segundo de los procedimientos de las vanguardias usado por Giménez Caballero en su retrato de Azaña fue el expresionismo esperpéntico tomado las caricaturas satíricas o la literatura humorística. Ningún elemento más significativo de la 'estetización de la política' en su fascismo de vanguardia (Corrella Lacasa 2000: 62; Benjamin 1992: 15-60) que la crítica al aspecto físico de la persona y a su carácter, en vez de la crítica racional a sus ideas y actuaciones políticas. Como ha estudiado Javier Domingo (1991: 160), Manuel Azaña fue con diferencia 'el reflejo más genuino de la república en chistes y viñetas humorísticas de los años treinta, periodo que comprende la etapa republicana en nuestro país. Como hombre del centro en el abanico político sirvió para escarnio de derechas y de izquierdas'.

La prensa satírica de la época había crecido y se había desarrollado al compás del capitalismo de edición español, tomando forma en los numerosos hebdomadarios de humor y viñetas publicadas en diarios de tirada nacional y provincial. El personaje de Azaña constituía el hombre-caricatura por excelencia, ya que por su protagonismo, su popularidad, su constitución física poco agraciada y sus cualidades como orador y polemista irónico, cáustico, estaba constantemente en el punto de mira de los observadores de su tiempo. Giménez Caballero tomará del expresionismo caricaturesco, brote germinal de la 'leyenda negra 
de Azaña, ${ }^{8}$ tres inspiraciones principales para sus propósitos propagandísticos denigratorios: el primer fuste de dicha leyenda será la etopeya deformante de la caracterización física - Azaña como monstruo - (Domingo 1991: 161-62); el segundo será la caracterización como tirano o como figura dictatorial, recurso que será usado tanto por el sindicato anarquista de la CNT, como por la derecha como la revista Gracia y Justicia (Domingo 1991: 162; Peña González 2008). La tercera inspiración será la mofa basada en los datos biográficos - ciertos o atribuidos -, no relacionados con ideas o actuaciones políticas, sino basados en su supuesto 'mal carácter' de escritor frustrado y resentido (Domingo 1991: 163).

Dejando a un lado estos dos últimos usos caricaturescos que, en cierto modo, ya se vieron cuando tratamos la lectura autobiográfica de los datos de ficción y la influencia de la literatura (para)científica de la época, puede resultar interesante detenerse un momento en el retrato de Manuel Azaña como 'monstruo'. El uso de la imagen es parte estructural de toda la obra, como se ha señalado, desde la misma portada. El libro se divide, además, en dos partes: 'La imagen latente' - los artículos publicados en prensa y recopilados para el libro -, y 'La imagen revelada'. En su 'Apunte casi definitivo', con el que Giménez acaba la primera parte señala 'haber dibujado con paciencia su figura, siguiéndola con cautela, goma de borrar, difumino y carbón' (59).

Sin embargo, es principalmente durante el primer capítulo de la segunda parte, 'Cartones de dibujo sobre Azaña', donde la influencia de la caricatura satírica resulta más evidente y declarada. Supone, también, una inflexión en el libro, que, habiendo apuntado hacia el panegírico de una imagen latente - la posibilidad de un Azaña como conductor de una revolución política autoritaria -, se convierte en una decepcionante 'Imagen de pleno relieve', en un análisis 'total y consuntivo: revelador' (Gímenez Caballero 1975: 62). Esta imagen es la de un demócrata, un falso líder autócrata, al que sólo cabe denigrar en un libelo, que lo desacredite y permita el paso al nuevo rey natural, al dictador, al Genio de España que Giménez Caballero ansía.

Lejos del hercúleo padre lleno de fuerza física que superara al resto de los machos de la manada, sometiese a las hembras, acabara con el 'matriarcado' y restaurase el 'patriarcado', presenta un Azaña de aspecto antiheroico: cabezón - en la doble acepción de testarudo y macrocéfalo - cabeza 'de piedra', 'de pedestal', 'de tribuna y de mesa presidencial' (67 y 68), llega a decir -, y de aspecto enfermizo, - 'abultada palidez con gafas', 'cabeza de cera', 'muy de

8 Son muchos los elementos constitutivos de esta 'leyenda negra', pero se ha señalado como uno de los hitos de la vesania antiazañista, la edición espúrea de Joaquín de Arrarás de los diarios robados durante la guerra y que iban aderezados de comentarios y citas copiadas del libro de Giménez Caballero y algunas caricaturas firmadas por 'Kin' (Azaña 1939). Joaquín de Alba y Santino ('Kin') había sido el autor de la ilustración de la portada de La República Jurdana (1934), sátira del destierro del Dr. Albiñana, fundador del Partido Nacionalista Español, desterrado por Azaña. En esta portada caricaturesca Azaña aparece disfrazado con un traje romano corto y con el saludo romano-fascista del brazo en alto. Para otros usos literario-humorísticos de la figura de Azaña en escritores fascistas, véase Albert 2003 y Peña González 2008. 
busto antiguo', como los 'rostros convulsos de sans-coulottes' decapitados (67) -. Manuel Azaña, lejos del apolíneo conductor que anhelara Giménez Caballero, tenía un cuerpo desproporcionado y débil. Estas ideas de debilidad son repetidas de nuevo al tratar de su pelo cano y su prominente calvicie (67), asociadas a la senectud, a una virilidad decadente. Su rostro, siguiendo las indicaciones de la endocrinología y la 'caracteriología' fisiognómica al uso, escondería algún tipo de desequilibrio hormonal que afectaría supuestamente a la virilidad del personaje y, por tanto, a su carácter y moralidad: 'Rasgos abultados, blandos, sensuales, sin aristez alguna. Se dirían rasgos de un tímido y linfático. Pero los labios son carniceros. La sonrisa, voraz y sin misericordia. La mirada, glacial, fina, profunda, lejana, implacable' (67).

Es decir, que la fealdad física mueve al asco, y al miedo debido a su rostro 'que asusta a los niños de España' y ‘da pavor' -. Giménez Caballero no se resiste a caer en el tópico caricaturesco de las verrugas hiperbólicas y 'cancerberas' de la cara de Azaña. Al igual que en el caso de Marco Tulio, que fue apodado Cicerón por sus verrugas faciales semejantes a garbanzos, la prensa satírica de la época, y tras ella Gecé, aplicaron con saña en el mismo problema estético cuando se trató de demonizar al repúblico alcalaíno (67).

Resulta curioso, por otro lado, el trato dado a la vestimenta de Azaña. Ésta es asociada, de modo despectivo, primero con el travestismo carnavalesco, y luego con sus ideas democráticas - máscaras, disfraces de su supuesto monocratismo secreto, por tanto -:

También cabeza cenobial de celda. (Un Carnaval, Azaña la disfrazó con traje de Cardenal, con vestimenta inquisitiva). Para disimularla en la calle, en la tremenda calle democrática, la traviste con un flexible, sombrero blando, mediocre, indiferente. El sombrero flexible de Azaña es la máscara con el que encareta su secreto totémico: indecible a los ojos ingenuos de las masas [...] Sus pantalones, casi siempre arrugados, plisados por el sedentarismo y el olvido del cuerpo, le denuncian siempre ese fenómeno sacerdotal. Azaña lo aprovecha para ejemplarizar sobre la democracia, sobre lo democrático y ejemplar que resulta en una República llevar arrugas en el rostro y el traje; sobre lo bien que sienta parecerse a un Herriot en lo estudiadamente desgarbado, fachoso y campechano (Giménez Caballero 1975: 68).

De nuevo, la cuestión de la virilidad asociada al cuerpo, relacionado éste al carácter y, por tanto, a la política, ha de llevar, una vez más, a la conclusión fascista: la democracia no es una forma 'viril' de conducir a un pueblo. Esto se confirma con el físico poco masculino del líder demócrata, un cuerpo propio para 'haldas sacerdotales’ o ‘toga de foro grecolatino' (68), que, sin estas ropas, se asemeja a

los cuerpos de los canónigos al quedarse de paisano: despistados, torpes, gruesos, excesivos, tímidos y sin saber qué hacer ni como andar. [...] Los brazos de Azaña suelen caer casi siempre a lo largo del cuerpo, relajadamente, como hechos de trapo y sin músculo, con bamboleo inmóvil de muñeco, enseñando el dorso laxo y blando de las manos. Manos que no se cierran en puños ni en garfios, sino que flotan abacial y cándidamente, destacando su albuna gordezuela sobre los puños del traje, como queriendo mostrar un anillo episcopal inexistente, como invitando al beso genuflexo - de ese anillo (68). 
Una vez más, el cuerpo, ahora insistentemente caracterizado como obeso, blando, pasivo, se combina con la demonización de la parte más peligrosa del físico de Azaña, su boca con dientes de ‘ferocidad sarcástica’ (67). Por ser la más atractiva, se diría que es la caracterizada de modo más subliminalmente viril, aunque también es tornada herida, debilidad casi femenina, castración, en los términos freudianos manejados por Giménez Caballero (Labanyi 1996: 380). La voz, sus discursos, son considerados, además, la característica más dañina para sus enemigos y también sale de su boca, la parte más castigada por los caricaturistas:

La voz de Azaña es clara y fría. Como una fuente.

Claridad pertinaz, metálica. Tan metálica, que se acera en cuchillo, y se clava en los cuellos y los costados. Apuñala. Fría y honda. Su frialdad, sólo se templa con sangre de heridas. Entonces, cuando la voz rojea - húmeda, goteante - se hace dulce, densa, pastosa, convulsa. Se llena como de amor. Emocionada y líquida. (Giménez Caballero 1975: 68)

Esta caracterización conduce a una conclusión brutal en el epílogo del libro, y que ya estaba contenida alegóricamente en el prólogo con la 'Fábula de los reyes naturales' que se suceden violentamente en el poder. Su conclusión, ya en 1932 , resulta demoledora: si Manuel Azaña no lleva a la República hacia un régimen de partido único, si los españoles no empujan al poder ejecutivo hacia ese camino, el resultado habría de llegar igual, no importa el modo. Les advierte Giménez Caballero: 'No repitamos la triste historia de aquel otro Urvater. Que por pequeñeces teóricas se le abandonó, se le negó colaboración, se le asesinó poco a poco. Si no queréis a Azaña, asesinadle de una vez, muerte gloriosa' (60).

El trabajo que Giménez Caballero se propone en su libro es propiciar la caída de Azaña, contribuyendo a forjar la leyenda negra que minara poco a poco las bases de su 'reinado'. Se sintió con el deber comprenderlo y 'de dominar' así lo comprendido, de no dejar al azar la 'caída violenta o exhaustiva' del poder de Azaña (62).

Si el personaje de El jardín de los frailes sirvió para ilustrar el presunto resentimiento de un escritor fracasado, en el epílogo Giménez Caballero recurre al paralelismo con Lorenzo, el personaje apuñalado en el drama La Corona. El autor expresa así su deseo propiciatorio, la aparición de un duque Aurelio que le prepare una emboscada al Lorenzo del drama azañesco (205). Ante el presentimiento pesimista de la 'imposibilidad de una esencia republicana para España', Ernesto Giménez Caballero se propone 'pronosticar que del caos gestatorio republicano del 14 de abril naciera fatalmente un nuevo mito monocrático’ (61). Poco importaba que el hombre que encarnaba el poder ejecutivo de la República no se ajustara a la toga cesárea diseñada en Genio de España:

El mayor pecado que se nos podrá achacar es el ansia íntima patriótica, delicada y desesperada de 'buscar a través de Azaña un héroe', de 'cuajar un héroe', de 'inventar el héroe' sobre el panorama triste, desierto y cobarde de España. Lo que menos importa a nuestro designio es la sustancia dada de un hombre determinado. Y lo que más: el dársela nosotros. Prestar poesía y grandeza a un transeúnte es tarea 
ingenua y noble para el poeta. Si este transeúnte traiciona nuestra poesía ..., tanto peor para él, para la historia y para los demás. Que no para nosotros, juglares de arpa nacional e ilusionada. Poesía y realidad será siempre el drama patético de quien sueña lo mejor y lo más alto para su patria (177).

El juglar era, como hemos señalado, un contrapirandelliano autor en busca de personaje, un vate en busca de un Orestes para su particular Orestiada (22). Mientras llegaba la aparición histórica de su ‘duque Aurelio', aprovechó para fundar la leyenda que comenzara la muerte política y física de Manuel Azaña y sus ideas: 'Nosotros los poetas de la Orestiada, los troveros de reyes naturales, sólo cantamos - contra el consejo prudente del clásico - "a señores que se nos puedan morir”. Porque sólo así, otros podrán nacer. Cumpliendo la fatalidad trágica y eterna de la leyenda' (25).

Pronto comprendió el error cometido con su libro sobre Manuel Azaña, más por precipitación que por falta de intención (Giménez Caballero 1979: 89, en Trapiello 2002: 435). No deja de tener cierto toque de humor negro su descarada nostalgia mussoliniana con la que concluyó, ya en el prólogo a la edición de 1975, su fracasada búsqueda del ‘duque Aurelio', de su Genio de España: 'Y el pueblo se frustró con Azaña, que era un burgués y un ateneísta. Con Prieto, un gordo pacifista. Y con Largo Caballero, que de Lenin tuvo muy poco. Sólo hoy queda el misterio de quién sea Franco’ (Giménez Caballero 1975: 11).

De estas palabras se puede deducir el deseo eternamente insatisfecho por cantar a 'un Hombre, un Jefe' (59) a cuya personalidad carismática pudiera rendir culto (Trapiello 2002: 59; Carbajosa and Carbajosa 2003: 76). Esta insatisfacción no acabó siquiera con la muerte de José Antonio Primo de Rivera o del dictador Francisco Franco. Durante la transición, el madrileño siguió su sucesiva búsqueda surrealista de ese ‘Hombre’ en Adolfo Suárez, Felipe González y hasta en Santiago Carrillo (Anon., 'El día de Cervantes. Giménez Caballero hablará sobre La hora de Don Quijote en el Ateneo': 25; Giménez Caballero 1980, en Serrano y San Luciano 1980: 95-120; Giménez Caballero 1977: 3).

Pese a lo infructuoso de la búsqueda, cabría añadir, que esta biografía fue más efectiva con su primer propósito propagandístico. En los años ochenta y noventa todavía se pudieron leer interpretaciones de Azaña influidas directamente por la de Giménez Caballero, que insistían en la caracterización surrealista (Tusell 1990: 57) del republicano como figura derechista o autoritaria (Jiménez Losantos 1990: XIV) y personaje monstruoso (Marañón 1980: 7). Y, en efecto, reafirma la efectividad literaria de este libelo propagandístico la determinación con la que algunos aún en el siglo XXI mantienen viva la leyenda negra de Manuel Azaña y la II República (Mainer 2006: 39-40; Espinosa Maestre 2005: 39; 61; 83). 


\section{Obras citadas}

Albert, Metchtchild, 2003. Vanguardistas de camisa azul. La trayectoria de los escritores Tomás Borrás, Felipe Ximénez de Sandoval, Samuel Ros y Antonio de Obregón entre 1925 y 1940 (Madrid: Visor Libros).

Anon., 1930 'Editorial España. Últimas publicaciones: Dos vidas extraordinarias. Confesiones de Clemenceau. por J. Martet. Traducción M. Azaña. [Publicidad]', El Sol. Diario independiente (18 de mayo): 2 .

—_, 1932a. 'González Ruiz, Nicolás. Azaña. Sus ideas religiosas. Sus ideas políticas. El hombre. Gráfica Universal, Evaristo San Miguel, 8. Madrid, 1932', Índice Literario. Archivos de Literatura Contemporánea (agosto), 1.2: 57.

— , 1932b. 'Biografía. Giménez Caballero. Manuel Azaña (Profecías sobre la República Española). Ediciones de La Gaceta Literaria', El Sol. Diario independiente (28 de octubre): 2.

— , 1932c. 'Giménez Caballero (E.), Manuel Azaña (profecías españolas), ed. de La Gaceta Literaria. Madrid', Índice Literario. Archivos de Literatura Contemporánea (diciembre), 1.5: 155-56.

— 1980 . 'El día de Cervantes. Giménez Caballero hablará sobre La hora de don Quijote en el Ateneo', $A B C$ (20 de abril): 25.

— y pensamiento de su tiempo', Anthropos, 84: 2-20.

—_, 1988. 'Bibiliografía de y sobre E. Giménez Caballero', Anthropos, 84: 29-33.

— , 1988. 'Ernesto Giménez Caballero. Informes y bibliografía temática', Anthropos, 84: 65-71.

Azaña Díaz, Manuel, 1939. Memorias íntimas de Azaña, con anotaciones de Joaquín Arrarás, con ilustraciones de Kin (Madrid: Ediciones Españolas).

—, 1983. Antología, 2: Discursos, 'Prólogo' y notas de Federico Jiménez Losantos (Madrid: Alianza Editorial).

— 1990. Obras Completas, ed. Juan Marichal, 4 vols. (Madrid: Ediciones Giner).

—_, 2004. Diarios Completos. Monarquía, República, Guerra Civil, con 'Introducción’ de Santos Juliá (Barcelona: Crítica).

Benjamin, Walter, 1992. Discursos Interrumpidos, I: Filosofía del arte y de la historia (Madrid: Taurus). Carbajosa, Mónica, y Pablo Carbajosa, 2003. La corte literaria de José Antonio. La primera generación cultural de la Falange, con 'Prólogo' de José-Carlos Mainer (Barcelona: Crítica).

Corrella Lacasa, Miguel, 2000. 'Ernesto Giménez Caballero, o la estetización de la política', Res Publica, Revista de Filosofía Política, 6: 57-70.

Domingo, Javier, 1991. 'Azaña y la prensa satírica en su época', Anuario del Departamento de Historia, UCM, 3: 159-65.

Espinosa Maestre, Francisco, 2005. El fenómeno revisionista o los fantasmas de la derecha española. Sobre la matanza de Badajoz y la lucha en torno a la interpretación del pasado (Badajoz: Los Libros del Oeste).

Eysenck, Hans Jürgen, 1988. Decadencia y caída del imperio freudiano (Barcelona, Nou Art Thor).

Foard, Douglas W., 1975. Ernesto Giménez Caballero (O la revolución del poeta): Estudio sobre el nacionalismo cultural Hispánico en el siglo XX (Madrid: Instituto de Estudio Políticos).

Freud, Sigmund, 1923. Totem y tabú; Un recuerdo infantil de Leonardo Da Vinci, trad. L. López-Ballesteros, en Obras completas del profesor S. Freud, vol. 8 (Madrid: Biblioteca Nueva).

Giménez Caballero, Ernesto, 1926. Carta de Ernesto Giménez Caballero a Guillermo de Torre, 5 de julio. Manuscrito depositado en la Biblioteca Nacional de España, Madrid, signatura Ms 22823/71.

— americana - internacional. Letras.arte.ciencia (1 de diciembre), 119: 3-4.

—_, 1932a. Genio de España. Exaltaciones a una resurrección nacional y del mundo (Madrid: Ediciones de La Gaceta Literaria).

—_, 1932b. Manuel Azaña. Profecías españolas (Madrid: Editorial La Gaceta Literaria).

—

—, 1933. 'Manuel Azaña', Gerarchia (julio): 562-70.

—

- 1935b. Arte y Estado (Madrid). 
—_, 1975. Manuel Azaña. (Profecías Españolas), Con prólogo a la edición de Ernesto Giménez Caballero y apéndice por Jean Becarud (Madrid: Ediciones Turner).

—, 1977. 'Comunismo y Europa', $A B C$ (26 de julio): 3.

- 1979. Memorias de un dictador (Barcelona: Editorial Planeta).

_ Edascal): 95-120.

—_, 2005. Casticismo, nacionalismo y vanguardia: (antología, 1927-1935). Selección y prólogo de José-Carlos Mainer (Madrid: Fundación Santander Central Hispano).

Giménez Caballero, Ernesto, y Enrique Selva Roca de Togores, 1988. 'Giménez Caballero entre la vanguardia y la tradición. Su autobiografía intelectual a través de una entrevista', Anthropos (mayo), 84: 21-26.

González Ruíz, Nicolás, 1932. Azaña, sus ideas religiosas, sus ideas políticas, el hombre (Madrid: Gráfica Universal).

Gubern, Román, 1999. Proyector de luna. La generación del 27 y el cine (Barcelona: Anagrama).

Jiménez Losantos, Federico, 1990. 'La derecha descreída', ABC Literario (3 de noviembre): XIV.

Labanyi, Jo, 1996. 'Women, Asian Hordes and the Threat to the Self in Gimenez Caballero's Genio de España', Bulletin of Hispanic Studies, 73.4: 377-88.

López-Vidriero, María Luisa, 1982. Bibliografía de E. Giménez Caballero (Madrid: Universidad Complutense).

Mainer, José-Carlos, 2006. Años de vísperas. La vida de la cultura en España (1931-1939) (Madrid: Espasa-Calpe).

_- Alfredo, 1932. 'Un libro de profecías españolas. Marinetti en Sevilla. Homenaje europeo. El drama y su tensión. Ante Una política de Azaña', Informaciones (26 de noviembre): 10.

Marañon, Gregorio, 1980. 'Azaña y un perfil', $A B C$ (7 de febrero): 70.

Martet, Jean, 1930. Confesiones de Clemenceau, trad. Manuel Azaña (Madrid: Editorial España).

Molero Asenjo, Antonio, 1910. Observaciones antropológicas de las Anomalías en los criminales (Guadalajara: Daniel Ramírez).

Pagliara, Maria, 2001. Scritture di vita. Biografie e Autobiografie del Novecento (Bari: Edizioni Giuseppe Laterza).

Peña González, Juan José, 2008. El único estadista: visión satírico-burlesca de Manuel Azaña (Madrid: Editorial Fundamentos).

Rocamora, Pedro, 1980. 'Don Quijote ante el mundo ( $y$ ante mi) de Giménez Caballero', $A B C$ (31 de enero): 25-26.

Rodriguez-Puértolas, Julio, 1986. Literatura Fascista Española (Madrid: Akal).

Salustio Crispo, Gayo, 1997. Conjuración de Catilina. Guerra de Jugurta, Fragmento de las Historias. Cartas a César. Invectiva contra Cicerón. Invectiva contra Salustio (Madrid: Gredos).

Santos, Dámaso, 1988. 'Ayer y nuevamente, Ernesto Giménez Caballero', Anthropos, 84: 34-37.

Santos Torroella, Rafael, 1988. 'Giménez Caballero y Dalí: influencias recíprocas de un tema compartido', Anthropos, 84: 53-56.

Sarfatti, Marguerita G., 1932 [1926]. DVX, 15a ed. (Milano: A. Mondadori Editore).

— 1938. Dux, con 'Introducción' de Ernesto Giménez Caballero, notas y trad. L. Horno Liria y C. M. Álvarez Peña (Zaragoza: Librería General, Im. Heraldo de Aragón).

Sedwick, Frank, 1963. The Tragedy of Manuel Azaña and the Fate of the Spanish Republic (Columbus, OH: Ohio State University Press).

Selva Roca de Togores, Enrique, 1991. 'Giménez Caballero en los orígenes ideológicos del Fascismo español', Estudis d'Història Contemporània del País Valencià, 9: 183-213.

—, 2000. Ernesto Giménez Caballero: entre la vanguardia y el fascismo (Valencia: Pre-textos).

Serrano, Carlos, 1993. 'Un curieux “Ami” Giménez Caballero face à Manuel Azaña', en Amalric, J.-P., and P. Aubert (eds.), Azaña et son temps. Colloque international organisé par la Ville de Montauban et le Centre National de la Recherche Scientifique tenu à Montauban du 2 au 5 novembre 1990 (Madrid: La Casa de Velázquez), pp. 193-201.

Stannard, David E., 1980. Shrinking History: On Freud and the Failure of Psychohistory (Oxford and New York: Oxford University Press).

Stoddard, Theodor Lothrop, 1926. La rebeldía contra la civilización, trad. C. Abreu (Madrid: Revista de Occidente). 
BHS, 88 (2011)

Tandy, Lucy, and Maria Sferrazza, 1977. Ernesto Giménez Caballero y La Gaceta Literaria: o la generación del 27 (Madrid: Turner).

Trapiello, Andrés, 2002. Las armas y las letras. Literatura y Guerra Civil (1936-1939) (Barcelona: Ediciones Península).

Tusell, Javier, 1990. 'La otra cara de don Manuel', ABC (4 de noviembre): 57.

Utrera Macías, Rafael, 1988. 'Cuatro secuencias sobre el cineasta Ernesto Giménez Caballero’, Anthropos, 84: 46-50.

Von Hentig, Hans, 1930. Robespierre: Estudio psicopatológico del impulso de dominio, con 'Prólogo', del Dr. Gonzalo R. Lafora, trad. García Díaz (Madrid: Editorial España). 